\title{
Redes Sociais Digitais e a Promoção da Saúde do Jovem
}

\section{Digital Social Networks and the Youth Healthcare}

Resumo: Este artigo discute alguns aspectos teóricos em torno das redes sociais digitais e seu uso na área da saúde. Apresenta também os resultados de pesquisa documental realizada no ano de 2011 , da produção bibliográfica brasileira sobre o tema das redes sociais digitais. Para tanto, foram analisados artigos, teses e dissertações publicados entre os anos de 2001 e 2011. Em termos metodológicos, utilizam-se ferramentas da internet e softwares estatísticos para o tratamento dos dados. Um dos resultados deste estudo contempla as limitações e fragilidades de pesquisas documentais sobre base de dados digitais. Outro resultado importante diz respeito ao perfil dos documentos analisados, que apresenta uma maior incidência nas áreas das Ciências Humanas e Sociais Aplicadas, com um grande aumento de documentos a partir do ano de 2005.

Palavras-chave: Redes Sociais Digitais. Jovem. Pesquisa Bibliográfica. Comunicação e Educação. Promoção da Saúde.

\begin{abstract}
This article discusses some theoretical issues around Digital Social Networks and healthcare. It also presents the results of documental research conducted in 2011 over Brazilian literature about DigitalSocial Networking. Articles, theses and dissertations published between 2001 and 2011 were analyzed. In terms of methodology was used some Internet tools and one statistical software for the treatment of the data. One result of this research was the limitations and weaknesses of documentary research on digital database. Another result concerns about the profile of the documents examined, which showed a high incidence in the areas of Humanities and Applied Social Sciences, with a large increase in 2005.
\end{abstract}

Keywords: Social Digital Networks. Bibliography research. Communication and Education. Health Promotion.

VERMELHO, Sônia Cristina Soares Dias; VELHO, Ana Paula Machado; BONKOVOSKI, Amanda Karine; PIROLA, Alisson Roberto. Redes Sociais Digitais e a Promoção da Saúde do Jovem. Informática na Educação: teoria e prática, Porto Alegre, v. 17, n. 1, p. 91-110, jan./jun. 2014.

\section{Sônia Cristina Soares Dias Vermelho \\ Centro de Ensino Superior de Maringá}

\author{
Ana Paula Machado Velho \\ Instituto Cesumar de Ciência, Tecnologia e Inovação
}

\section{Amanda Karine Bonkovoski \\ Centro de Ensino Superior de Maringá}

Alisson Roberto Pirola
Universiddode de Brosí

\section{Como tudo começou}

$\mathbf{T}$

oda pesquisa é iniciada de um ponto que, pelo movimento do cotidiano, em geral, se perde no tempo. A idealização do projeto de pesquisa que originou este artigo aconteceu num desses momentos que (quase) se perdeu: o encontro de dois grupos de pesquisa num determinado contexto. Um pesquisava a comunicação na era digital e outro a mídia educação. $\mathrm{O}$ encontro aconteceu quando os pesquisado- 
res integraram o Mestrado em Promoção da Saúde, programa interdisciplinar que possui uma linha de pesquisa envolvendo as áreas de educação e comunicação voltadas à promoção da saúde.

O desafio colocado aos dois grupos, inicialmente, foi encontrar o ponto de intersecção entre áreas específicas no campo da saúde, tais como nutrição, fisioterapia, educação física, fonoaudiologia, com as áreas de educação e comunicação. O ponto de articulação com a educação e a comunicação emergiu de forma mais tranquila após um processo de reconhecimento entre os pesquisadores, em relação ao que cada uma dessas áreas, vinculadas à saúde, poderia realizar no campo da Promoção da Saúde. O resultado desse trabalho foi a definição de que o papel das áreas de educação e comunicação, em termos de pesquisa dentro do programa, é o de investigar quais são as estratégias educacionais e comunicacionais mais eficientes para atingir os dois públicos prioritários do programa: jovens em idade escolar e idosos. Posteriormente, o conteúdo das ações educacionais e comunicacionais serão os resultados das demais áreas específicas do campo da saúde.

A partir desse desafio, na primeira etapa, definiram-se quais os fundamentos e experiências de uso das Tecnologias da Informação e Comunicação Digitais (TICD's) com potencial para se tornar uma ferramenta educacional e comunicacional.

\subsection{0 recorte da pesquisa}

Indiscutivelmente, as TICD's transformaram radicalmente os hábitos de consumo de mídia de boa parcela da população. Atualmente, as instituições públicas e privadas com atu- ação em todos os setores da sociedade têm adotado as TICD 's conectadas à internet como o veículo prioritário para atingir o seu público-alvo. Esse fato, aliado à ampla bibliografia sobre mídias já estudada e produzida pelos dois grupos, motivaram e sustentaram a definição do escopo da pesquisa que seria realizada. Assim, ficou estabelecido que as TICD 's seriam o objeto de investigação dos pesquisadores, com um recorte em torno das ferramentas de socialização disponíveis na internet, mais conhecidas como redes sociais. Delimitado o tema, foi elaborado um projeto de pesquisa estruturado em duas etapas: a primeira, de cunho bibliográfico e, a segunda, de campo. Neste primeiro momento, a proposta era conhecer as produções científicas brasileiras, ao longo dos últimos dez anos, sobre redes sociais (termo adotado provisoriamente) e saúde.

Essa etapa inicial pode ser justificada pela necessidade de apropriação, pelo grupo, do que já havia sido produzido sobre o tema por pesquisadores de instituições brasileiras. Partiu-se da hipótese de que estudos sobre o uso das redes sociais que utilizam as ferramentas da internet na área da saúde já haviam sido feitos e, assim, interessava compreender os limites e as potencialidades dessas ferramentas para ações de educação e comunicação para a promoção da saúde de jovens.

Pretendia-se, portanto, encontrar resultados que pudessem mostrar quais contribuições o grupo poderia trazer para o avanço da área, ou seja, eles não queriam ficar "reinventando a roda", como se diz em linguagem popular.

Dentro do escopo da pesquisa, a segunda etapa previa a realização de estudos ou investigações de campo com jovens e idosos, visando analisar, com maior profundidade, aspectos relacionados à usabilidade de algumas redes sociais para esses dois públicos. $O$ grupo op- 
tou por analisar a Usabilidade, pois, segundo bibliografia estudada,para o sucesso no acesso à informação, a interface deve apresentar aderências aos critérios de Usabilidade, que é a forma de medir o quão amigável é o sistema (PRESSMAN, 1995). A usabilidade, portanto, garante a continuidade e afirmação de um sistema de informação na perspectiva da interação com o usuário (COSTA, 2010).

Nesse sentido, parte-se da hipótese de que as ferramentas mais utilizadas não são, necessariamente, as que apresentam as melhores avaliações em termos de qualidade da interface humano-computador.

O objetivo, deste modo, era que as duas etapas do trabalho trouxessem subsídios conceituais, metodológicos e tecnológicos para fundamentar as atividades futuras do grupo de pesquisa na proposição de ações educacionais e comunicacionais com o uso das redes sociais. Até o momento da elaboração deste artigo, foi possível finalizar a primeira etapa, quanto à segunda, ainda está em fase de execução com previsão de término em agosto de 2013.

Por que o uso das redes sociais como ferramenta estratégica para a promoção da saúde do jovem? Porque é a ferramenta de circulação de informação da contemporaneidade. Para Lemos (2003), este momento é caracterizado pela cibercultura, que se consolidou entre as décadas de 1980 e 1990 com a informática de massa e a popularização da internet, que teve maior força após a criação da World Wide Web (WWW), em 1991.

Essas novas tecnologias permitiram a criação de meios de comunicação mais interativos, liberando os indivíduos das limitações de espaço e tempo, tornando a comunicação mais flexível. Os jovens são integrantes da cultura digital ou cibercultura, num modelo de comunicação que se dá pela convergência de mídias.
É a tradução da tecnocultura, definida por Sodré (2005, p.13), como um processo em que as trocas simbólicas que viabilizam a comunicação de qualquer natureza são mediadas por signos estritamente vinculados à evolução tecnológica.

É importante, também, lembrar que esse cenário é alicerçado na ideia da participação (KOTTLER, 2010). Segundo o autor, em decorrência do fácil acesso às informações e às tecnologias de comunicação, as pessoas passaram a ter mais liberdade para expressar suas opiniões, podem participam de forma ativa dentro das mobilizações e trocar informações constantemente. Este cenário apresenta um desafio para os profissionais da comunicação que precisam não só proporcionar experiências empolgantes para o público, como também buscar a transformação da sociedade.

Além das questões de cunho social, o Brasil é o quinto país no ranking mundial, onde as pessoas mais procuram orientações sobre saúde na internet. Este dado foi revelado numa pesquisa da Bupa Health Pulse, publicada no jornal O Globo em janeiro de 2011. Entre os países pesquisados - Brasil, Austrália, Grã-Bretanha, China, França, Alemanha, Índia, Itália, México, Rússia, Espanha e Estados Unidos - foi identificado que $81 \%$ das pessoas que têm acesso à internet usam a rede para obter orientações sobre saúde, remédios ou condições que necessitem cuidados médicos. Em função desses e outros aspectos, definiu-se que esta pesquisa teria como foco as redes sociais.

\subsection{Marco conceitual da pesquisa}

É importante para o grupo conceituar, primeiramente, o que é a Promoção da Saúde, 
entendida como um processo de capacitação da comunidade para atuar na melhoria de sua qualidade de vida e saúde, com maior participação no controle desse processo. Os documentos emitidos por orientadores da área de Promoção da Saúde entendem que, para atingir um estado de completo bem-estar físico, mental e social, os indivíduos e grupos devem saber identificar aspirações, satisfazer necessidades e modificar favoravelmente o ambiente.

Neste contexto, a saúde é um recurso para a vida, assume um caráter positivo, pois busca enfatizara necessidade de potencializar os recursos sociais, naturais e pessoais para garantir um estado de bem-estar individual e coletivo. Deste modo, promover a saúde deixa de ser responsabilidade exclusiva do setor saúde, transformando-se em um objetivo a ser alcançado por vários outros setores que atuam, em particular na formação e informação da população.

Essa conceituação foi construída ao longo de várias décadas e tem nos documentos oriundos das conferências internacionais e regionais da área de Promoção da Saúde (OMS, 1986; 1980; 1988; 1991; 1992; 1997; 1998; 2000) seu fundamento conceitual e operacional. O Brasil lançou, em 2006, o Plano Nacional de Promoção da Saúde, porque se tornou evidente a necessidade de configurar uma política pública capaz de atender aos desafios dos problemas de saúde da população, bem como da própria estrutura da saúde pública brasileira, o SUS.

Em termos operacionais, a Promoção da Saúde visa ao fortalecimento de uma política transversal, integrada e intersetorial, que promova a interlocução entre o setor da saúde e a sociedade, compondo redes de compromisso e corresponsabilidade na formulação de propostas e ações para garantir a qualidade de vida da população. Como afirma o documento brasileiro, para isso deve haver uma articulação "[...] sujeito/coletivo, público/privado, estado/ sociedade, clínica/política, setor sanitário/outros setores, visando romper com a excessiva fragmentação na abordagem do processo saúde-adoecimento e reduzir a vulnerabilidade, os riscos e os danos que nele se produzem" (BRASIL, 2006, p. 15).

O desafio que se coloca é encontrar as estratégias adequadas para operacionalizar essa articulação, haja vista que tradicionalmente as áreas têm uma atuação isolada, operando cada qual dentro do seu marco regulatório. Essa política foi identificada como incapaz de resolver os problemas enfrentados pelo modelo econômico e de socialização adotado pela sociedade atual e tem trazido consequências à saúde. Um exemplo clássico são os hábitos alimentares estimulados pelos mais diversos meios para o consumo de produtos que causam prejuízos ao organismo, mas que está associado a um estilo de vida: urbano e moderno.

Por conseguinte, a política de Promoção da Saúde propõe, entre outras coisas, que cada um consiga identificar e desenvolver suas potencialidades e habilidades pessoais. Para que isso aconteça é necessário que a população tenha acesso à informação, todavia de maneira que consiga se transformar num processo de formação (educação) para a saúde. É notório que somente o acesso à informação não é suficiente para que a população mude seus hábitos. Um exemplo dessa problemática é o consumo de cigarro. Por mais que o Ministério da Saúde divulgue informações sobre os prejuízos do uso desse produto, foram necessárias medidas coercitivas para diminuir o consumo. A mudança de hábito é um processo bem mais complexo e prolongado, não se trata somente de informar, mas de (trans)formar um sujeito. 
Nessa premissa, as políticas de Promoção da Saúde, ainda que reconheçam as limitações das ações de comunicação em saúde, compreendem sua necessidade, mas preferencialmente dentro de um contexto mais eficaz para "apreender" o sujeito, no sentido de sensibilizá-lo em relação ao conteúdo da peça midiática. $\mathrm{O}$ que se pretende e se espera é que aumentem as opções de circulação de informações, para que a população possa, uma vez sensibilizada, apropriar-se dessas orientações e exercer maior controle sobre sua própria saúde,visando, em última instância, adotar hábitos mais saudáveis.

Para exemplificar, com maior clareza, a importância de ações de promoção da saúde, destaca-se a questão alimentar. Um dos públicos mais vulneráveis à adoção de hábitos nocivos à saúde é o jovem, em particular os adolescentes. Isso em função dos apelos mercadológicos para o consumo de produtos comestíveis industrializados, largamente ofertados em todos os espaços coletivos e, às vezes,também no doméstico. A questão alimentar é estratégica para a saúde pública, afinal a alimentação nas primeiras fases da vida define, em grande medida, a qualidade em termos de saúde nas etapas posteriores, em particular na terceira idade.

Desta forma, a falta de cuidado da população jovem com a alimentação hoje,trará, com muita probabilidade, um alto impacto sobre os gastos com saúde pública nas próximas décadas. Quanto o sistema público de saúde será capaz de absorver é uma incógnita, sabe-se que é um problema de primeira ordem e que deve ser enfrentado. O principal indicador é o crescimento dos índices de obesidade observados nas últimas décadas em adolescentes.

E a questão se agrava porque, atualmente, a obesidade entre os jovens brasileiros é encontrada nas diferentes faixas econômicas, mas principalmente, naquelas de classe mais alta. Esse fato pode ser explicado em função de que a "[...] classe socioeconômica influencia a obesidade por meio da educação, da renda e da ocupação, resultando em padrões comportamentais específicos que afetam ingestão calórica, gasto energético e taxa de metabolismo" (MELLO, 2004, p. 173-4). Ou seja, não se trata de "falta de informação", visto que a classe social mais abastada tem acesso aos mais diversos recursos comunicacionais e educacionais.

Assim, persiste o desafio de organizar estudos e pesquisas para identificação, análise e avaliação de ações de promoção da saúde. Ações que operem, não só dentro das estratégias mais amplas definidas nas diretrizes da Política Nacional de Promoção da Saúde (integralidade, equidade, responsabilidade sanitária, mobilização e participação social, intersetorialidade, informação, educação e comunicação e sustentabilidade), mas que também sejam eficazes do ponto de vista psicossocial.

Outro desafio que se vislumbra é lidar com o conceito de Redes Sociais. O termo tornou-se palavra-chave na ordem do dia em se tratando deTICD's. Seu uso transcorreu áreas e destruiu fronteiras sendo apropriado hoje por muitos campos de investigação. Uma delas, a área da comunicação. Termos como Rede Social, mídia social, mídia integrada etc. estão sendo utilizadas na busca de explicações sobre os fenômenos comunicacionais da atualidade.

A complexidade e diversidade conceitual e prática em torno da nova configuração tecnológica-comunicacional pós-internet e seu impacto nos processos comunicacionais vêm sendo discutida por inúmeros autores (LEMOS, 2003; HARVEY, 1994; BRANCO E MATSUZAKI, 2011; BENKLER，2006; THEVENO，2007; GREYSEN, 
KIND E CHRETIEN, 2010; KAPLAN e HAENLEIN, 2010; SCHROCK, 2009; KIETZMANN et al., 2011; PRETTO E SILVEIRA, 2008).

A partir da bibliografia estudada, o grupo de pesquisa compreendeu que o termo que melhor expressa o aparato tecnológico e os processos comunicacionais realizados a partir dessa base física está sob a rubrica de "Rede Social Digital". Além da pesquisa bibliográfica, uma averiguação informal com estudiosos espalhados pela Europa e Estados Unidos, com os quais o grupo tem relações, constatou que este é o termo mais corrente. Adotado, também, nos países da América Latina, Portugal, França e Espanha. Nos Estados Unidos é mais comumente utilizado o conceito de social media. Porém, encontra-se também na literatura o termo social networks; "mídia social" ou sosia alinen media na Finlândia.

Para os trabalhos realizados por estes pesquisadores, portanto, foi adotado o conceito de Rede Social Digital que define a macroestrutura tecnológica que dá suporte a um conjunto de atores sociais (sujeitos e instituições). Estes devem estar conectados por laços sociais (BATISTA, 2012; RAHME, 2010; FREUD, 1976, 1997), formados, mantidos e reforçados (ou não) por meio de interações sociais (VYGOTSKY, 1989, 1987; BAKHTIN, 1988; LURIA, 1987). As interações são realizadas dentro de uma relação de troca de conteúdos, os quais podem ser criados pelas mais diferentes linguagens disponíveis no formato digital: textual, sonora, audiovisual e imagética. As Redes Sociais Digitais potencializam a manutenção e a expansão dos laços sociais, além de ajudar a visualizar as redes de relacionamento da qual cada sujeito faz parte.

Quanto à educação, tomou-se como referência Freire (2009) em particular o texto Pedagogia da Autonomia. Além dos princípios relacionados com a prática docente discutida neste texto,dois aspectos parecem centrais para discutir a vinculação das áreas de comunicação e educação. A primeira diz respeito ao ponto de vista defendido pelo autor de que não existe ensino sem pesquisa. Tanto para a ação docente quanto discente, a pesquisa é inerente ao ato de educar. Isso traz um primeiro laço em relação à comunicação: os conteúdos a serem pesquisados estão em algum suporte comunicacional, por conseguinte conhecer, compreender e saber manipular os suportes comunicacionais existentes na sociedade atual é de extrema importância para que se concretize de forma ampla a pedagogia proposta por Paulo Freire.

Em segundo lugar, o autor também alerta para o fato de que o docente é um profissional do seu tempo. Isso significa que os contextos sociais, econômicos e tecnológicos devem ser considerados para se pensar a ação educativa. Neste sentido, é prudente que a educação incorpore em suas práticas os veículos de comunicação que passam a ser inseridos nas práticas sociais, visto que esses armazenarão conteúdos a serem pesquisados por alunos e professores.

Em particular a rede internet, com as inúmeras ferramentas de armazenamento e circulação de dados, tornou-se uma fonte de pesquisa bastante democrática (ainda que se tenham várias questões a serem discutidas em torno do seu caráter democratizante). Além de um repositório de conteúdos, a segunda geração da internet, a WEB 2.0, incorporou ferramentas que permitiram revolucionar a estrutura de comunicação mundial: sai de uma estrutura de comunicação Broadcast (produção centralizada de conteúdo e disseminada para a massa) para uma estrutura Selfcast, em que todos têm o potencial de ser produtor de conteúdo e este 
pode ser disseminado para a massa ou para grupos específicos.

Quanto à comunicação, os pesquisadores buscaram suporte em Sodré (2007) para esclarecer o que se entende desse conceito. Segundo o autor,

[...] o termo "comunicação" designa dois processos: primeiro o de pôr em comum as diferenças por meio do discurso, com ou sem auxílio da retórica (processo comunicativo); segundo, o de interpretar os fenômenos constituídos pela ampliação tecnológica da retórica, isto é, a mídia, na sociedade contemporânea (processo comunicacional) (SODRÉ, 2007, p. 22).

Assim, o cerne da questão em relação à comunicação não é o processo de veiculação de acontecimentos por intermédio dos meios que está em jogo, mas o próprio "[...] o funcionamento articulado das tradicionais instituições sociais com a mídia", o que leva a uma "[...] mutação sociocultural centrada no funcionamento atual das tecnologias da comunicação" (id, p. 26).

A centralidade de tratar as atuais TICD's como estratégicas para todas as áreas, portanto, é fundamental para um projeto de sociedade mais justa, democrática e fraterna.

\section{Metodologia da pesquisa}

A metodologia adotada nesta etapa da pesquisa é de cunho quanti-qualitativo, de base bibliográfica e, para investigação (coleta de dados) foi empregada a técnica de análise de conteúdo. A natureza do material bibliográfico é de artigos, teses e dissertações.

Para o desenvolvimento, utilizaram-se dos seguintes procedimentos: identificar os textos a serem lidos no período de 2001 a 2010 em bases de dados digitais; selecionar os textos pelos títulos; fazer a leitura integral dos artigos; identificar as categorias descritivas e analisar o material pesquisado. Além das duas pesquisadoras, o grupo ainda contou com dois bolsistas de iniciação científica do curso de Sistemas de Informação.

A definição da metodologia para o levantamento dos dados mostrou-se um processo bastante complexo. Após analisar alguns trabalhos com objetivos semelhantes (ROCHA, 1999; MESSINA, 1998; FERREIRA, 2002; ANDRÉ \& ROMANOWSKI, 2002, VERMELHO \& AREU, 2005), estabeleceu-se que os artigos seriam lidos na íntegra, porque nem sempre artigos de periódicos possuem resumos. Também ficou definido na metodologia que todos os textos a serem analisados deveriam estar disponíveis na internet: os artigos em periódicos, as teses e as dissertações. Como a pesquisa está inserida no campo da Promoção da Saúde, foram incluídas todas as bases de dados da área disponíveis na instituição. Com isso, as bases pesquisadas para a seleção dos artigos foram: Biblioteca Virtual da Saúde, Lilacs, IBECS, MedLine, Scielo, Cesumar, UEM, Portal da Capes.

Para as buscas, foram definidas as seguintes palavras-chaves: educação, comunicação, tecnologia da informação, promoção da saúde, redes sociais e web 2.0. A escolha das palavras-chaves deu-se fundamentalmente pela impossibilidade de utilizar somente o termo "redes sociais". A busca pelo termo trouxe um resultado muito distinto daquele que se gostaria de obter, uma vez que na área da saúde as "redes sociais" compreendem estratégias de atuação dos profissionais em comunidades, sem necessariamente significar qualquer vín- 
culo com o uso de tecnologia. Optou-se, deste modo, por ampliar os termos de busca para tentar identificar artigos que tivessem relação com o tema de pesquisa: o uso das redes so- ciais digitais com o público jovem para ações de educação em saúde ou comunicação em saúde. O resultado das buscas por palavras-chaves nas bases de dados digitais foi o seguinte:

Tabela 1. Resultados com os totais de artigos encontrados nas buscas por palavras-chaves nas bases de dados digitais

\begin{tabular}{|c|c|c|c|c|c|c|c|}
\hline Plataforma & Educação & Comunicação & $\begin{array}{l}\text { Tecnologia da } \\
\text { Informação }\end{array}$ & $\begin{array}{l}\text { Promoção da } \\
\text { Saúde }\end{array}$ & $\begin{array}{l}\text { Redes So- } \\
\text { ciais }\end{array}$ & $\begin{array}{c}\text { WEB } \\
2.0\end{array}$ & TOTAIS \\
\hline Biblioteca Virtual em Saúde & 413.003 & 172.882 & 3.430 & 61.559 & 1.288 & - & 652.162 \\
\hline Lilacs & 25.938 & 6.411 & 461 & 7.112 & 422 & - & 40.344 \\
\hline IBESC & 2.550 & 795 & 63 & 446 & 69 & - & 3.923 \\
\hline MedLine & 354.153 & 161.278 & 2.282 & 44.847 & 523 & - & 563.083 \\
\hline Scielo & 10.842 & 2.737 & 84 & 430 & 76 & 7 & 14.176 \\
\hline Cesumar & 207 & 48 & 14 & 15 & 5 & 10 & 299 \\
\hline UEM & 500 & 173 & 43 & 88 & 18 & 22 & 844 \\
\hline CAPES & 17.093 & 4.482 & 227 & 1.118 & 204 & 474 & 23.598 \\
\hline TOTAIS & 824.286 & 348.806 & 6.604 & 115.615 & 2.605 & 513 & 1.298 .429 \\
\hline
\end{tabular}

Diante da grande quantidade de artigos selecionados e da impossibilidade de analisar esse volume, realizou-se ocruzamento com as palavras-chaves por meio do conectivo + , cujo resultado encontra-se na Tabela 2 .

Tabela 2. Resultados dos cruzamentos realizados nas buscas por palavras-chaves nas bases de dados digitais

\begin{tabular}{|c|c|c|c|c|c|c|c|c|c|c|}
\hline $\mathrm{N}$. & TERMOS DE BUSCA & BVS & Lilacs & IBESC & MedLine & Scielo & Cesumar & UEM & CAPES & Total \\
\hline 1 & Educação + Comunicação & 8363 & 765 & 32 & 7020 & 489 & 8 & 22 & 784 & 17483 \\
\hline 2 & Educação + Tecnologia da Informação & 243 & 63 & 7 & 141 & 3 & 4 & 6 & 23 & 490 \\
\hline 3 & Educação + Promoção da Saúde & 6921 & 1359 & 62 & 4249 & 156 & 5 & 18 & 262 & 13032 \\
\hline 4 & Educação + Redes Sociais & 111 & 36 & 4 & 28 & 4 & 0 & 3 & 16 & 202 \\
\hline 5 & Educação + Web 2.0 & 0 & 0 & 0 & 0 & 3 & 1 & 1 & 8 & 13 \\
\hline 6 & Comunicação + Tecnologia da Informação & 335 & 83 & 8 & 195 & 13 & 4 & 15 & 52 & 705 \\
\hline 7 & Comunicação + Promoção da Saúde & 1408 & 265 & 5 & 982 & 38 & 0 & 4 & 59 & 2761 \\
\hline 8 & Comunicação + Redes Sociais & 55 & 17 & 1 & 29 & 5 & 1 & 3 & 22 & 133 \\
\hline 9 & Comunicação + Web 2.0 & 0 & 0 & 0 & 0 & 1 & 4 & 4 & 5 & 14 \\
\hline 10 & Tecnologia da Informação + Promoção da Saúde & 28 & 8 & 1 & 11 & 0 & 0 & 0 & 0 & 48 \\
\hline 11 & Tecnologia da Informação + Redes Sociais & 8 & 4 & 2 & 1 & 0 & 0 & 0 & 4 & 19 \\
\hline 12 & Tecnologia da Informação + Web 2.0 & 0 & 0 & 0 & 0 & 0 & 4 & 2 & 0 & 6 \\
\hline 13 & Promoção da Saúde + Redes Sociais & 64 & 40 & 0 & 5 & 1 & 0 & 4 & 2 & 116 \\
\hline 14 & Promoção da Saúde + Web 2.0 & 0 & 0 & 0 & 0 & 0 & 0 & 0 & 0 & 0 \\
\hline & Total & 17536 & 2640 & 122 & 12661 & 713 & 32 & 82 & 1240 & 35026 \\
\hline
\end{tabular}


A partir desse resultado, fez-se análise de uma amostra aleatória dos títulos dos artigos encontrados nos cruzamentos com maior número de indicações (linhas 1, 3 e 7); identificados, novamente, não atendiam aos objetivos da pesquisa. Diante da dificuldade encontrada, definiu-se por recortar a pesquisa em torno dos termos de busca das linhas 4, 8, 11 e 13, mais de acordo com os objetivos da pesquisa.

Os 470 artigos foram analisados pelos títulos e palavras-chaves e, destes, procurou-se criar uma listagem de 101 publicações lidas na íntegra e analisadas. A última seleção gerou uma lista de 49 artigos. Após essa etapa, o material foi analisado novamente e catalogado por meio de instrumento de pesquisa na forma de Ficha Catalográfica, desenvolvido por Vermelho e Areu (2005), o que possibilitou codificar e categorizar seu conteúdo.

A análise de conteúdo, segundo Gibbs (2009), é um processo analítico fundamental para pesquisas desta natureza, e, basicamente, consiste em identificar uma ou mais passagens do texto que exemplifiquem alguma ideia temática para identificá-la a um conjunto de códigos. São eles que, posteriormente, permitem referência taquigráfica a uma ideia temática. Os dados de análise de conteúdo foram digitados em planilhas no Excel e, na sequência, importados para software estatístico SphinxLexica V 5.0. Utilizado para analisar o conjunto da produção, ou seja, para realizar a análise léxica e de conteúdo de forma automatizada, segundo a metodologia proposta por Gibbs (2009), além de realizar os cruzamentos entre as variáveis.

Em relação às teses e dissertações, o levantamento foi feito exclusivamente no site do Instituto Brasileiro de Informação em Ciência e Tecnologia (Ibict), na base de dados Biblioteca Digital Brasileira e Teses e Disser- tações (BDTD), em outubro de 2011. Os estudos foram realizados no modo Pesquisa Básica, com a palavra-chave "Redes Sociais", encontrados 4.923 trabalhos. O número excessivo de publicações obrigou a fazernova busca, acrescentando o adjetivo "digital". O resultado foi uma lista de 133 trabalhos, dentre os quais, selecionados 115 após a leitura dos títulos e resumos. Na Tabela 3, encontra-se a distribuição por tipo de trabalho.

Tabela 3. Distribuição do número de trabalho por tipo.

\begin{tabular}{|c|c|c|}
\hline Tipo de Trabalho & Freq. & $\%$ \\
\hline Dissertação & 86 & $74,80 \%$ \\
\hline Tese & 29 & $25,20 \%$ \\
\hline TOTAL OBS. & 115 & $100 \%$ \\
\hline
\end{tabular}

Antes de apresentar os resultados da pesquisa é importante ressaltar os problemas encontrados ao longo do trabalho.

Certamente, a maior dificuldade foi localizar as publicações que tivessem aderência ao tema. Em razão, fundamentalmente, de o cadastro dos trabalhos nas bases de dados seguirem padrões distintos. No caso das teses e dissertações, os pesquisadores tentaram realizar buscas em sites das universidades, tais como o da USP, UFRGS, Unicamp etc. Contudo, a estrutura dos metadados das respectivas bases inviabilizou um tratamento homogêneo às buscas. Em cada uma dessas instituições, existem dados distintos sobre os trabalhos e, mesmo em termos de tecnologia, as permissões para os acessos são distintos e, com isso, trazem resultados diferentes.

Deste modo, a opção foi coletar as informações somente na base de dados doIbict para garantir uma uniformidade na pesquisa, mesmo diante da possibilidade de excluir inúmeras publicações sobre o tema, armazenados nas bases de dados das demais instituições. Além 
disso, sabe-se que algumas instituições que tem programas de pós-graduação stricto sensu demoram no envio dos trabalhos defendidos em seus respectivos programas para oIbict. Portanto, das teses e dissertações encontradas, pode-se ter deixado de lado várias produções que não foram encontradas nas buscas por duas razões: porque ainda não estavam armazenados na base de dados do Ibict ou não utilizaram os termos "redes sociais" ou "redes sociais digitais" na definição dos metadados e resumos. Portanto, os resultados encontrados são em torno do corpus definido para essa pesquisa e se tem consciência das limitações que isso acarreta para as conclusões sobre os resultados.

Quanto aos artigos, a situação foi ainda mais complexa. Os termos de busca definidos para a pesquisa "redes sociais digitais", igualmente, nem sempre aparecem nos itens de indexação, em razão, fundamentalmente, de dois aspectos. O primeiro, discutido anteriormente,ligado à falta de consenso em relação ao conceito. Cada área/autor utiliza uma definição para as redes sociais e, por conseguinte, associa a produção oriunda das pesquisas aos termos adotados. O segundo aspecto, consequência do primeiro, é que isso vai ampliar um problema já existente e reincidente acerca da configuração das bases de dados digitais.

Existe uma recomendação para que se utilizem padrões e normas para a indexação de objetos digitais na internet, atendendo, assim, às necessidades da sociedade atual, além de garantir sua manutenção e democratização. Esses padrões estão definidos na ISO 15.836/2003 e ISO 15.836/2009 e, no Brasil, por meio do documento da "Carta para a Preservação do Patrimônio Arquivístico Digital", de 2004 (MALARD, 2004). A falta de uma padronização, tanto conceitual quanto tecnológica, dificulta enormemente as pesquisas em torno dos materiais disponíveis na internet.

A recuperação de objetos digitais para outros trabalhos e pesquisas, tais como as pesquisas de "Estado da Arte",pode ser inviabilizada em função da impossibilidade de acesso. Diante de aumento exponencial que a rede tem alcançado nos repositórios de dados e objetos. A diversidade de indexação desses objetos cria uma grande dificuldade para o pesquisador que pretende buscar os dados a partir de um conjunto de palavras-chaves.

As questões relacionadas com a estrutura da internet são objetos de investigação em vários centros de pesquisa. A Université de Technologie de Compiègne, França, possui um Laboratório de Pesquisa Interdisciplinar (Costech), para pesquisas e discussões acerca dos problemas, limitações das ferramentas de navegação e dos motores de busca disponíveis aos usuários (PFAËNDER \& JACOMY, 2011). É notório a necessidade construir ferramentas computacionais mais eficazes para melhorar as estratégias de acesso aos objetos depositados na Web, repercutindo nos resultados das buscas. Isto está relacionado com a forma como os dados são armazenados.

É sabido que não existe controle sobre o que é publicado na internet. Isso faz com que não exista uma padronização em relação aos metadados daquilo que é depositado na rede. Essa falta de padronização traz problemas sérios para o desenvolvimento de pesquisa do tipo bibliográfica, pois o acesso aos artigos e demais tipos de trabalhos científicos se dão por meio de sistemas de buscas (buscadores) incapazes de cobrir toda a produção depositada na internet. Com isso, realizar pesquisas do tipo Estado da Arte hoje é tarefa recoberta de contradição: por uma lado, temos um acesso extremamente facilitado com a internet e os 
repositórios existentes na rede; por outro, a falta de padronização daquilo que é depositado fragiliza o sistema de busca dos materiais. Neste sentido é que defendemos ser fundamental estimularum melhor desempenho da rede para que,futuramente, a comunidade possa realizar tais pesquisas com mais segurança e confiabilidade. Por ora, infelizmente, vive-se um contexto em que a ampliação do acervo digital está inversamente proporcional à qualidade do acesso a esse acervo. Quanto maior o volume incorporado à rede maior é a complexidade para tornar o acervo acessível a todos.

Contudo, ainda que se conheçam as limitações impostas pela própria tecnologia, deve-se considerar que as pesquisas de levantamento e análise de material bibliográfico contribuem significativamente para traçar panoramas (ainda que reconhecidamente parciais) sobre temas investigados dentro de uma comunidade científica. Segundo os cânones da pesquisa científica, este tipo de trabaIho se caracteriza como Estudo Formulativo e Exploratório(ANDER-EGG, 1974)e têm como funções básicas: formular problemas; desenvolver hipóteses; familiarizar o investigador com o tema ou fenômeno que deseja pesquisar; reunir informações para definir investigações posteriores; ou seja, são fundamentais para estabelecer a situação sobre determinado campo de pesquisa. Este tipo de estudo pode ser desenvolvido a partir de duas fontes de dados: a) os documentais e b) com os contextos em si, ou de campo. A pesquisa aqui elaborada foi formatada para utilizar na sua primeira etapa os dados documentais e na segunda, os de campo.

\section{Perfil dos artigos e demais traba- Ihos publicados na internet}

Para este artigo, foram analisados dados do instrumento de coleta que definem o perfil da produção bibliográfica sobre "redes sociais digitais", entre os anos de 2001 a 2011. O instrumento era formado por 21 campos, entre questões abertas e fechadas.

Na Tabela 3, apresentamos os resultados, em termos de distribuição nos anos de publicação dos trabalhos.

Tabela 3. Distribuição do número de artigos e teses/ dissertações por ano de publicação

\begin{tabular}{|c|c|c|c|c|}
\hline \multirow{2}{*}{ Ano } & \multicolumn{2}{|c|}{ Artigos } & \multicolumn{2}{c|}{ Teses e Dissertações } \\
\cline { 2 - 5 } & Freq. & $\%$ & Freq. & $\%$ \\
\hline 2000 & 1 & $2,00 \%$ & - & - \\
\hline 2001 & - & - & 1 & $0,90 \%$ \\
\hline 2002 & 1 & $2,00 \%$ & 1 & $0,90 \%$ \\
\hline 2003 & 1 & $2,00 \%$ & 3 & $2,60 \%$ \\
\hline 2004 & 9 & $18,40 \%$ & 5 & $4,30 \%$ \\
\hline 2005 & 2 & $4,10 \%$ & 6 & $5,20 \%$ \\
\hline 2006 & 4 & $8,20 \%$ & 9 & $7,80 \%$ \\
\hline 2007 & 3 & $6,10 \%$ & $\mathbf{1 3}$ & $\mathbf{1 1 , 3 0 \%}$ \\
\hline 2008 & 2 & $4,10 \%$ & $\mathbf{1 9}$ & $\mathbf{1 6 , 5 0} \%$ \\
\hline $\mathbf{2 0 0 9}$ & $\mathbf{7}$ & $\mathbf{1 4 , 3 0} \%$ & $\mathbf{1 8}$ & $\mathbf{1 5 , 7 0 \%}$ \\
\hline $\mathbf{2 0 1 0}$ & $\mathbf{1 4}$ & $\mathbf{2 8 , 6 0} \%$ & $\mathbf{1 6}$ & $\mathbf{1 3 , 9 0 \%}$ \\
\hline $\mathbf{2 0 1 1}$ & $\mathbf{5}$ & $\mathbf{1 0 , 2 0} \%$ & $\mathbf{2 1}$ & $\mathbf{1 8 , 3 0 \%}$ \\
\hline TOTAL & 49 & $100 \%$ & 115 & $100 \%$ \\
\hline
\end{tabular}

Estes dados permitem visualizar um aumento gradativo de teses e dissertações sobre o tema a partir da metade dos anos 2000. Os artigos aparecem com aumento maior em 2009, com pico isolado no ano de 2004. É importante lembrar que o ano de 2004 foi marcado por alguns acontecimentos que se acredita ter contribuído para ascensão do tema naquele ano, tais como: a criação do Orkut; a prolife- 
ração da web 2.0, que proporciona a troca de informações entre indivíduos; e a popularização da ADSL.

É certo que, a pesquisa na pós-graduação, a partir do ano de 2004, marca um crescimento contínuo de trabalhos sobre o tema. A quantidade de artigos, porém, não se reflete no mesmo crescimento, fato que, entre outros,pode ser atribuído à dificuldade de acesso aos mesmos; à dispersão em termos de veículo nos quais foram publicados; por terem sido publicados em outra língua; ou mesmo, não terem no título, nas palavras-chaves ou no resumo o termo "redes sociais" com ou sem o adjetivo "digitais".

Quanto ao tipo de estudo, ilustrado na Tabela 4 , pode-se avaliar que, nos artigos há predominância das sistematizações teóricas, enquanto nos textos das teses e dissertações houve uma leve preponderância das pesquisas de campo. É importante ressaltar neste quesito dois aspectos: primeiro o que se define no instrumento como "Sistematização Teórica" e como "Pesquisa de Campo". Os pesquisadores optaram por classificar como "Pesquisa de Campo" aquela na qual a investigação para coleta de dados, visando à elaboração do artigo/tese/dissertação, ocorra com pessoas, instituições ou empresas; bem como classificada como "Sistematização teórica" os artigos/ teses/dissertações em que a produção tenha utilizado, somente, fontes documentais, como por exemplo,as revisões de bibliografia.

Nessa categoria foram incluídas também as pesquisas de desenvolvimento de sistemas/ softwares. Entende-se que o desenvolvimento de um sistema/software é uma produção intelectual que se concretiza num produto gerado a partir de uma sistematização teórica e não, de uma coleta de dados e tratamento dos mesmos. Ainda que para a criação de um siste- ma sejam necessárias pesquisas bibliográficas, porém estas não constituem o objeto de investigação em si e tampouco os resultados são extraídos desse corpus de material bibliográfico. Tendo em vista o tema das redes sociais digitais abarcar produções oriundas da área de informática, vários trabalhos que foram classificados como "sistematização teórica" são descrições de sistemas implementados ou analisados.

Outro problema que deve ser relatado diz respeito a grande quantidade de artigos nos quais não há referência à metodologia utilizada na pesquisa e que deu origem aos dados, ou mesmo a empregada para a elaboração do artigo.

O fato de constar, assim, número maior de trabalhos teóricos nos artigos se deve, em grande medida, a falta de explicitação no texto do método utilizado na pesquisa, levando os pesquisadores, obrigatoriamente, a classificá-lo como "Sistematização teórica".Infelizmente, nem todos os periódicos exigem para publicação um tópico descrevendo a metodologia da pesquisa. Isso é um problema da produção bibliográfica brasileira em algumas áreas, aspecto que já havia sido identificado e relatado na pesquisa realizada por Vermelho e Areu (2005). Na Tabela 4 os resultados.

Tabela 4. Distribuição quanto tipo de pesquisa realizado e descrito nos artigos e teses/dissertações.

\begin{tabular}{|c|c|c|c|c|}
\hline \multirow{2}{*}{$\begin{array}{c}\text { Estrutura da } \\
\text { pesquisa }\end{array}$} & \multicolumn{2}{|c|}{ Artigos } & \multicolumn{2}{c|}{$\begin{array}{c}\text { Teses e } \\
\text { Dissertações }\end{array}$} \\
\cline { 2 - 5 } & Freq. & $\%$ & Freq. & $\%$ \\
\hline $\begin{array}{c}\text { Pesquisa de } \\
\text { campo }\end{array}$ & 8 & $16,30 \%$ & $\mathbf{6 9}$ & $\mathbf{6 0 , 0 0 \%}$ \\
\hline $\begin{array}{c}\text { Sistematização } \\
\text { Teórica }\end{array}$ & $\mathbf{4 1}$ & $\mathbf{8 3 , 7 0 \%}$ & 46 & $40,00 \%$ \\
\hline TOTAL OBS. & 49 & $100 \%$ & 115 & $100 \%$ \\
\hline
\end{tabular}


Quanto à área de produção dos textos, a distribuição está descrita na Tabela 5. Importante salientar que a classificação do artigo/ tese/dissertação entre as áreas foi feita com base nas seguintes informações: nos artigos, a classificação foi em função da área em que o periódico está vinculado e, no caso das teses e dissertações, em função dos programas stricto sensu em que foram defendidas. Em ambos, as áreas predominantes foram a educação e a comunicação. Essas áreas correspondem a quase metade da produção sobre o tema.

É interessante observar, também, que as Ciências Humanas e Sociais Aplicadas aparecem com percentuais acima das demais áreas. Esse cenário permite que sejam formuladas algumas hipóteses de trabalho para futuras pesquisas. Por exemplo, as questões envolvendo as redes sociais digitais, que interferem nas dinâmicas sociais, estão instigando pesquisadores para entender o fenômeno, pois as mesmas atuam diretamente sobre o objeto dessas áreas da ciência: o sujeito e seu meio.

A área de Ciências Exatas, por seu turno, não aparece com os maiores percentuais, muito embora não seja possível identificar a totalidade do perfil da produção dessa área, isso porque, o que é desenvolvido de tecnologia para a internet deve estar indexado por outros termos, tais como: criação de agentes, datamining, buscadores etc. A Tabela 5apresenta os resultados da distribuição pelas áreas do conhecimento.
Tabela 5. Distribuição do número de artigos/teses/ dissertações por área de investigação.

\begin{tabular}{|c|c|c|c|c|}
\hline \multirow{2}{*}{ Área da Ciência } & \multicolumn{2}{|c|}{ Artigos } & \multicolumn{2}{c|}{$\begin{array}{c}\text { Teses e } \\
\text { Dissertações }\end{array}$} \\
\cline { 2 - 5 } & Freq. & $\%$ & Freq. & $\%$ \\
\hline $\begin{array}{c}\text { Ciências da } \\
\text { Comunicação }\end{array}$ & $\mathbf{1 0}$ & $\mathbf{2 0 , 4 0 \%}$ & $\mathbf{2 9}$ & $\mathbf{2 5 , 2 0 \%}$ \\
\hline Educação & $\mathbf{1 0}$ & $\mathbf{2 0 , 4 0 \%}$ & $\mathbf{3 0}$ & $\mathbf{2 6 , 1 0 \%}$ \\
\hline Antropologia & 7 & $14,30 \%$ & 2 & $1,70 \%$ \\
\hline $\begin{array}{c}\text { Ciência da } \\
\text { Informação }\end{array}$ & 7 & $14,30 \%$ & 13 & $11,30 \%$ \\
\hline $\begin{array}{c}\text { Ciências da } \\
\text { Saúde }\end{array}$ & 6 & $12,20 \%$ & 2 & $1,70 \%$ \\
\hline Ciência Política & 3 & $6,10 \%$ & & \\
\hline $\begin{array}{c}\text { Ciências da } \\
\text { Computação }\end{array}$ & 3 & $6,10 \%$ & 15 & $13,00 \%$ \\
\hline Linguística & 2 & $4,10 \%$ & 2 & $1,70 \%$ \\
\hline Sociologia & 1 & $2,00 \%$ & 0 & $0 \%$ \\
\hline Administração & 0 & $0 \%$ & 5 & $4,30 \%$ \\
\hline Artes Visuais & 0 & $0 \%$ & 6 & $5,20 \%$ \\
\hline Ciências Sociais & 0 & $0 \%$ & 3 & $2,60 \%$ \\
\hline Design & 0 & $0 \%$ & 1 & $0,90 \%$ \\
\hline Engenharias & 0 & $0 \%$ & 2 & $1,70 \%$ \\
\hline Geografia & 0 & $0 \%$ & 1 & $0,90 \%$ \\
\hline Letras & 0 & $0 \%$ & 1 & $0,90 \%$ \\
\hline Psicologia & 0 & $0 \%$ & 3 & $2,60 \%$ \\
\hline TOTAL OBS. & 49 & $100 \%$ & 115 & $100 \%$ \\
\hline
\end{tabular}

Os pesquisadores também analisaram, na produção levantada, qual o aspecto estudado das redes sociais digitais. É importante ressaltar que o grupo discutiu demoradamente sobre a forma como faria a análise do conteúdo dos textos, propriamente dito, dos assuntos, dos temas e dos sujeitos etc. Como a leitura seria realizada por diversas pessoas, buscou-se definir algumas variáveis que interessavam, particularmente, aos pesquisadores. Por exemplo, era importante para o grupo saber se os textos tratavam da relação do sujeito com a rede social, ou o impacto que a mesma traria, ou, ainda, os usos das redes e da motivação que as pessoas teriam para utilizá-la. Portanto, para uniformizar a leitura dos integrantes da pesquisa, foi criado um campo específico intitulado "Aspectos Analisados da Rede". Na Tabela 6, apontam-se os resultados desse item. 
Tabela 6. Distribuição do número de Artigos e Teses/Dissertações por aspecto analisado em relação à rede social.

\begin{tabular}{|c|c|c|c|c|}
\hline \multirow{2}{*}{$\begin{array}{l}\text { Aspecto anali- } \\
\text { sado em torno da } \\
\text { Rede Social }\end{array}$} & \multicolumn{2}{|c|}{ Artigos } & \multicolumn{2}{|c|}{$\begin{array}{c}\text { Teses e } \\
\text { Dissertações }\end{array}$} \\
\hline & Freq. & $\%$ & Freq. & $\%$ \\
\hline Não se enquadra & - & - & 58 & $50,40 \%$ \\
\hline $\begin{array}{l}\text { Impacto social/ } \\
\text { psicológico do } \\
\text { uso/consumo da } \\
\text { Rede }\end{array}$ & 22 & $44,90 \%$ & 22 & $19,10 \%$ \\
\hline $\begin{array}{l}\text { Motivação para } \\
\text { uso/consumo da } \\
\text { Rede }\end{array}$ & 6 & $12,20 \%$ & 8 & $7,00 \%$ \\
\hline $\begin{array}{l}\text { Relação do su- } \\
\text { jeito com a Rede }\end{array}$ & 18 & $36,70 \%$ & 26 & $22,60 \%$ \\
\hline Uso da Rede & 27 & $55,10 \%$ & 25 & $21,70 \%$ \\
\hline TOTAL OBS. & 49 & 0 & 115 & 0 \\
\hline \multicolumn{5}{|c|}{$\begin{array}{l}\text { A quantidade de citações é superior } \\
\text { à quantidade de onsercações devido } \\
\text { às respostas múltiplas (4 no máximo). }\end{array}$} \\
\hline
\end{tabular}

Pode-se observar que os interesses que predominaram nos trabalhos analisados dizem respeito ao uso que se faz das redes sociais, o impacto social e/ou psicológico do uso da rede social, bem como da relação do sujeito com a mesma. O resultado é coerente ao se pensar que as áreas com mais publicações foram as Ciências Humanas e Sociais Aplicadas, as quais se voltam para aspectos culturais, de uso e consumo de produtos disponibilizados para a sociedade e os impactos que isso pode trazer.

Localizar a procedência dessas produções, também, é de interesse do grupo. Contudo, em razão dos problemas com o processo de coleta de dados, conforme relatado anteriormente, definiu-se por utilizar somente os trabalhos no formato de tese/dissertação, pois estes dariam confiabilidade quanto à origem da pesquisa.

Foram 28 instituições citadas, sendo 12 da região Sudeste, sete da região Sul, seis da região Nordeste e três da região Centro-Oeste. Já de imediato é possível observar uma predominância das produções localizadas nas regi- ões Sudeste e Sul não só em termos de quantidade, como também do número de textos encontrados (Tabela 7). Em outras pesquisas realizadas com base nacional (VERMELHO \& AREU, 2005) foi identificado o mesmo quadro para um período de análise dos anos 1982 a 2002. Nesse período, as pesquisas foram feitas nas áreas de educação e comunicação e suas variantes teórico-metodológicas (Tecnologia da informação e comunicação na educação, mídia educação, educomunicação, pedagogia da comunicação, da mídia etc.). O quadro de distribuição da produção científica brasileira se repetiu em relação ao tema das redes sociais digitais, mostrando que ainda permanece, na produção teórica brasileira, uma divisão entre as regiões, com forte adensamento nas regiões Sudeste e Sul, onde também se concentra o maior número de programas de pós-graduação.

Tabela 7. Distribuição das Teses/Dissertações por Instituição de origem.

\begin{tabular}{|c|c|c|}
\hline Instituição de origem & Freq. & $\%$ \\
\hline PUCSP & $\mathbf{2 0}$ & $\mathbf{1 7 , 4 0 \%}$ \\
\hline USP & $\mathbf{1 6}$ & $\mathbf{1 3 , 9 0 \%}$ \\
\hline UFRGS & $\mathbf{1 5}$ & $\mathbf{1 3 , 0 0 \%}$ \\
\hline UNICAMP & 9 & $7,80 \%$ \\
\hline UFMG & 8 & $7,00 \%$ \\
\hline UFC & 5 & $4,30 \%$ \\
\hline UFBA & 4 & $3,50 \%$ \\
\hline UFPB & 4 & $3,50 \%$ \\
\hline PUCRS & 4 & $3,50 \%$ \\
\hline UNB & 3 & $2,60 \%$ \\
\hline UDESC & 3 & $2,60 \%$ \\
\hline UNISINOS & 3 & $2,60 \%$ \\
\hline
\end{tabular}

Além das universidades citadas na tabela, aparecem UCB, UFPE, PUCRIO, UFRJ e Mackenzie, com dois trabalhos. Com apenas um trabalho aparecem: UFGO, UFAL, Universidade Católica de Salvador, UFSC, Universidade de Caxias do 
Sul, UTFPR, UTP, Soc.Educ. Braz Cubas, UERJ, UESC, Unimesp. Considerando as três instituições com maior número de produções encontradas, a PUCSP apresentou 12 pesquisas sobre o tema na área de Ciências da Comunicação, a USP com cinco trabalhos na área de Ciências da Informação e seis na área de Ciências da Computação; e, a UFRGS predominou nas áreas de Ciências da Computação com três trabalhos e educação com cinco.

\section{Redes, saúde e jovens}

Em se tratando do conteúdo propriamente dito, realizamos a categorização conforme propõe Gibbs (2009). Para atender a metodologia proposta, somente uma pessoa do grupo elaborou a categorização. A construção das categorias é um processo de análise que utiliza um conjunto de perguntas que são feitas ao texto durante a leitura de maneira que seja possível construir "blocos" de conteúdos. Das respostas a essas perguntas são criados índices descritivos que possibilitem posteriormente construir as categorias de análise. Para este trabalho criamos uma categorização descritiva do corpus da pesquisa.

Uma das categorias criadas foi "Sujeito". Por Sujeito compreende-se a pessoa, instituição, teoria, sistema, ferramenta etc., de quem ou de onde foram extraídos os dados ou informações para a composição do texto. Dentro dos propósitos da pesquisa, foram definidas, a priori, algumas categorias de Sujeito que são fundamentais: Rede Social Digital (discriminando qual delas), Crianças/Jovens/ Adolescentes, Educadores, Sistemas/Software e Internautas. Os demais sujeitos encontrados e não citados na Tabela 8 foram ignorados porque não havia interesse para os propósitos desse trabalho. Contudo, foram anotados em campo específico do tipo Aberto Texto e posteriormente tabulados.

Na Tabela 8, a seguir, são apresentados os resultados em relação à categoria Sujeito. Importante salientar que os percentuais representam a quantidade de indicações que cada uma das categorias teve em relação ao total de artigos/teses/dissertações. Com isso, os totais dos documentos e dos percentuais não podem ser apresentados, pois não representam à totalidade dos documentos analisados.

Tabela 8. Distribuição quanto aos sujeitos identificados nos artigos e teses/dissertações.

\begin{tabular}{|c|c|c|c|c|}
\hline Sujeito & $\begin{array}{c}\text { Arti- } \\
\text { gos }\end{array}$ & \% & $\begin{array}{c}\text { Tese / } \\
\text { Disser- } \\
\text { tação }\end{array}$ & \% \\
\hline $\begin{array}{c}\text { Crianças/Jovem/ } \\
\text { Adolescente }\end{array}$ & 19 & $39 \%$ & 24 & $21 \%$ \\
\hline Rede Social Digital & 12 & $24 \%$ & 28 & $24 \%$ \\
\hline Internautas & 9 & $18 \%$ & 21 & $18 \%$ \\
\hline Software/Sistemas & 5 & $10 \%$ & 23 & $20 \%$ \\
\hline Educadores & 4 & $8 \%$ & 7 & $6 \%$ \\
\hline
\end{tabular}

Dentre os artigos analisados, as crianças/ jovens/adolescentes foram citados como sujeitos em 39\% deles; para as teses e dissertações as redes sociais digitais tiveram maior incidência, com 24\%. Interessante analisar que as categorias não apresentam grandes diferenças em termos percentuais, exceto a dos Educadores, que teve pouca incidência tanto nos artigos quanto nas teses e dissertações, e os software/sistemas no caso dos artigos.

\section{Considerações finais}

Certamente, as considerações não podem ser tratadas como finais por dois aspectos: primeiro, por se tratar de uma pesquisa em andamento: a primeira etapa está finalizada, 
mas a segunda não.Segundo, porque os dados coletados certamente já sofreram alterações desde o momento de sua coleta até a publicação deste artigo. A dinamicidade da produção sobre o tema, bem como de sua disponibilização na internet são enormes.

Contudo, a experiência da pesquisa do tipo "Estado da Arte", que era o propósito inicial, mostrou-se praticamente inviável no contexto das bases de dados disponíveis atualmente. $\mathrm{E}$ essa experiência, com todos os problemas e limitações sofridos, trouxe ao grupo uma série de ensinamentos fundamentais para a prática da pesquisa documental com o uso da rede internet. Alguns sites se mostraram mais confiáveis em termos de mecanismo de busca: o site da base de periódicos Scielo, apesar de algumas limitações, possui um acervo considerável. Porém, não abrange a totalidade dos periódicos científicos, o que obriga a busca nos demais sites do próprio periódico, que muitas vezes não está alocado na página da instituição na qual está vinculado.

Infelizmente, no Brasil, ainda carecemos de uma padronização e centralização dos periódicos científicos em grandes bases de dados. A área da saúde, ainda, é mais privilegiada por possuir a Biblioteca Virtual em Saúde (BVS), que congrega boa parte das bases de dados de periódicos. Porém, o mecanismo de busca da BVS não é muito eficiente, o que acarreta um sobre trabalho para analisar os resultados. O Ibict apresenta uma ferramenta importante no processo de pesquisa, tendo em vista que indica ao lado do documento o percentual de aderência ao termo pesquisado. Essa ferramenta ajuda sobremaneira as pesquisas dessa natureza. Enfim, são estruturas e interfaces distintas e isso amplia a complexidade e a ocorrência de inconsistências nas pesquisas.

Ficou claro que, mesmo as instituições de pesquisa mais avançadas do País, ainda neces- sitam progredir muito para conseguir disponibilizar suas produções de forma segura e confiável. Problemas de padronização de dados e de interface são praticamente intransponíveis em situações como a que foi observada pelo grupo de pesquisa. Isso mostra uma grande contradição vivida atualmente: apesar dos avanços da web 2.0 e dos grandes repositórios de conteúdos, há necessidade de mecanismos de busca mais eficazes e de um processo de padronização de dados. Além desses aspectos, outro que se considera mais difícil de superar é a utilização dos conceitos e, consequentemente, dos termos de busca. O uso de termos distintos para tratar do mesmo objeto, situação que acontece com muita frequência quando o objeto é tratado por mais de uma área do conhecimento.

No caso dessa pesquisa, as redes sociais digitais foram denominadas por termos distintos e isso causa enormes transtornos para os estudos documentais. Porém, considera-se que esse aspecto poderá ser superado à medida que o objeto seja mais ampla e profundamente estudado. Aos poucos, espera-se que a ciência atue em convergência conceitual, pelo menos, para tratar desses novos arranjos trazidos pelas tecnologias da informação e comunicação digitais, como as redes sociais digitais.

Quanto aos resultados em si, o perfil da produção sobre as redes sociais digitais tem mostrado grande crescimento nos últimos anos. É interessante ressaltar que, apesar de ser um artefato tecnológico, as Ciências Humanas e Sociais Aplicadas tem se debruçado sobre o assunto, haja vista a incidência de documentos encontrados nestas duas áreas do conhecimento. São achados que abrem caminhos para novos projetos de pesquisa, pois levam a perguntas que não se pode responder nesta pesquisa, tais como: quais os fundamentos teóricos utilizados nessas pesquisas? Quais as 
conclusões que chegaram os autores? É possível encontrar consenso entre os resultados? $\mathrm{O}$ que motivou essas pesquisas? Os interesses em torno das redes sociais digitais ao longo dos anos foram se mantendo ou alterando? Enfim, inúmeras outras perguntas podem ser feitas sobre esses documentos. O importante é que essa base de dados encontra-se organizada e poderá ser utilizada para estudos comparativos futuros.

Também é relevante salientar que o fato do grupo de pesquisa ser interdisciplinar, com trajetórias em áreas distintas, mas que se soma- ram nesse processo foi fundamental superar algumas dificuldades conceituais e metodológicas. As áreas da educação e da comunicação se somaram a da Saúde para produzir novos conhecimentos. É nesta perspectiva que se está apostando, de investir num trabalho interdisciplinar. $\mathrm{O}$ fato de os, pesquisadores, terem origem em uma diversidade de áreas não foi nenhum empecilho para trabalhar juntos de forma exitosa. Ao contrário: foi (e vem sendo) fundamental para o sucesso das pesquisas que grupo realizou juntos no campo interdisciplinar da Promoção da Saúde.

\section{Referências}

ANDER-EGG, Ezequiel. 4. ed. Introducion a las técnicas de investigación social. Buenos Aires: Humanitas, 1974.

ANDRE, M.; ROMANOWSKI, J. (2002). O tema formação de professores nas dissertações e teses (19901996). Formação de Professores no Brasil. Brasília: MEC/INEP/COMPED, 2002, v. 1, p. 17-156.

BAKHTIN, M. Marxismo e filosofia da linguagem. São Paulo: Hucitec, 1988.

BATISTA, Antônio Augusto Gomes. Notas sobre a reflexão sociológica da psicanálise. Disponível em: http://www.institutopsicanalise-mg.com.br/psicanalise/almanaque/04/ textos/A\%20 reflex\%C3\%A30\%20social.pdf. Acesso em: 10 ago. 2012.

BENKLER, Y. The wealth of networks: how social production transforms markets and freedom. New Haven and London: YaleUniversity Press. 2006.

BRANCO, C. F.; MATSUZAKI, L. Olhares da Rede. São Paulo: Momento Editorial, 2009. Disponível em: http://www.culturaderede.com.br. Acesso em: 3 dez. 2011.

BRASIL. Ministério da Saúde. Secretaria de Vigilância em Saúde. Política Nacional de Promoção da Saúde. Brasília: Ministério da Saúde, 2006. 
COSTA, Luciana Ferreira; RAMALHO, Francisca Arruda. A usabilidade nos estudos de uso da informação: em cena usuários e sistemas interativos de informação. Perspect. ciênc. inf. v. 15, n. 1 Belo Horizonte, Apr. 2010.

FERREIRA, N. As pesquisas denominadas "Estado da Arte". Educação e Sociedade, ano XXIII, n. 79, ago. 2002.

FREIRE, Paulo. Pedagogia da autonomia: Saberes Necessários à Prática Educativa. Disponível em: http://www.sabotagem.revolt.org. Acesso em: 12.02.2009.

FREUD, Sigmund O mal-estar na civilização. Rio de Janeiro: Imago, 1997.

Psicologia de grupo e a análise do ego. In: Obras Psicológicas Completas de Sigmund

Freud: Edição Standart Brasileira, v. XVIII, Rio de Janeiro: Imago, 1976 [1921].

GIBBS, G. Análise de dados qualitativos. Porto Alegre: ArtMed, 2009.

GREYSEN, S. R.; KIND, T.; CHRETIEN, K. C. Online Professionalism And The Mirror Of Social Media. Gen Intern Med. 2010 Nov; 25(11):1227-9. Epub, 2010 Jul 15. [Pubmed - Indexed For Medline].

HARVEY, David. Condição Pós-Moderna: uma pesquisa sobre as origens da mudança cultural. 4. ed. Tradução: Adail Ubirajara Sobral e Maria Stela Gonçalves. São Paulo: Edições Loyola, 1994.

KAPLAN, A. M.; HAENLEIN, M. Users of the world, unite! The challenges and opportunities of Social Media. Business Horizons, 53 (1), 2010. Disponível em: http://www.sciencedirect.com/science/article/ pii/S0007681309001232. Acesso em: 12 jul. 2012.

KIETZMANN, J. H. et al. Social media? Get serious! Understanding the functional building blocks of social media. Business Horizons (2011) 54, 2011. Kelley School of Business, Indiana University.

KOTLER, Philip. Marketing 3.0: As Forças que Estão Definindo o Novo Marketing Centrado no Ser Humano. Rio de Janeiro: Editora Elsevier, 2010.

LEMOS, André. Cibercultura. Alguns pontos para compreender a nossa época. In: LEMOS, André; CUNHA, Paulo (Orgs.). Olhares sobre a Cibercultura. Porto Alegre: Sulina, 2003.

LURIA, A. R. Pensamento e Linguagem. Porto Alegre: ArtMed, 1987.

MALARD, R. Interoperabilidade de conteúdos didáticos digitais: uma contribuição à questão dos padrões. Curitiba, 145 p., 2004. Dissertação Pontifícia Universidade Católica do Paraná. 
MELLO, Elza D. de; LUFT, Vivian C.; MEYER, Flavia. Obesidade infantil: como podemos ser eficazes?. J. Pediatr. (Rio J.) [online]. 2004, vol.80, n.3, pp. 173-182. ISSN 0021-7557. http://dx.doi.org/10.2223/ JPED. 1180 .

MESSINA, G. Estúdio sobre el estado Del arte de la investigación acerca de la formación docente en los noventa. México, 1998. Mimeo.

OMS. Organização Mundial de Saúde. Declaração do México, 2000.

Rede de Megapaíses, 1998.

Declaração de Jacarta, 1997.

Declaração de Santafé de Bogotá, 1992.

Declaração de Sundsvall, 1991.

Declaração de Adelaide, 1988.

Carta de Ottawa, 1986.

Declaração de Alma-Ata, 1978.

PFAËNDER, Fabien; JACOMY, Mathieu. Explorer et appréhender le web. Disponivel em : http:// uv4you.free.fr/docs/Visualisation\%20information/ Explorer\%20et\%20appr\%E9hender\%20le\%20 web_Rochebrune2006.pdf. Acesso em: 18 jul. 2011.

PRESSMAN, R. S. Engenharia de software. São Paulo: Markron Books, 1995.

PRETTO, Nelson de Luca; SILVEIRA, Sérgio Amadeu (Org.). Além das redes de colaboração: internet, diversidade cultural e tecnologias do poder Salvador: EDUFBA, 2008.

RAHME, Mônica M. F. Laço social e educação: um estudo sobre os efeitos do encontro com o outro no contexto escolar. Tese, USP, Educação. São Paulo: s.n., 2010.

ROCHA, E. C. A pesquisa em educação infantil no Brasil: trajetória recente e perspectiva de consolidação de uma pedagogia. Florianópolis: UFSC, Centro de Ciências da Educação, Núcleo de Publicações, 1999. 
SCHROCK, A. Examining social media usage: technology clusters and social network site membership. First Monday - Reviewed journals on the Internet. V. 14, n. 1-5 January 2009. Disponível em: http://frodo.lib.uic.edu/ojsjournals/index.php/fm/index. Acesso em: 3 de dez. 2011.

SODRÉ, M. Sobre a episteme comunicacional. MATRIZes, n. 1, out. 2007, p. 15-26.

Reinventando a Cultura: a comunicação e seus produtos. São Paulo: Editora Vozes, 2005.

THEVENO, G. Blogging as a social media. Tourism and Hospitality Research, v. 7, 3/4, 282-289, 2007.

VERMELHO, S. C.; AREU, G. Estado da arte da área de Educação \& Comunicação em periódicos brasileiros. Educação e Sociedade, v. 26, 2005, p. 1413-1434.

VYGOTSKY, L. S. A Formação Social da Mente. São Paulo: Martins Fontes, 1989.

Pensamento e Linguagem. São Paulo: Martins Fontes, 1987.

Submetido para avaliação em 24 de agosto de 2012.

Aprovado para publicação em 24 de agosto de 2013.

Sônia Cristina Soares Dias Vermelho: Professora Titular do Centro de Ensino Superior de Maringá - Maringá PR - Brasil. E-mail: cristina.vermelho@gmail.com

Ana Paula Machado Velho: Pesquisadora do Instituto Cesumar de Ciência, Tecnologia e Inovação - Maringá - PR - Brasil. E-mail: anapaula_mac@gmail.com

Amanda Karine Bonkovoski: Graduada em Sistemas de Informação pelo Centro de Ensino Superior de Maringá Maringá - PR - Brasil. E-mail: amandabonko@hotmail.com

Alisson Roberto Pirola: Mestrando Bolsista (CAPES) da Universidade de Brasília - Brasília - DF - Brasil. E-mail: pixwel@gmail.com 